\title{
NEW EXPERIMENTAL EVIDENCE ON THE INCOMPLETE TRANSFORMATION PHENOMENON IN STEEL
}

\author{
F.G. Caballero ${ }^{1}$, C. Garcia-Mateo ${ }^{1}$, M.J. Santofimia ${ }^{2,3}$, M.K. Miller ${ }^{4}$ and C. García de \\ Andrés ${ }^{1}$
}

\footnotetext{
${ }^{1}$ Materalia Research Group, Department of Physical Metallurgy, Centro Nacional de Investigaciones Metalúrgicas (CENIM-CSIC), Avda. Gregorio del Amo, 8. E-28040 Madrid, Spain

${ }^{2}$ Materials Innovation Institute (M2i), Mekelweg 2, 2628CD Delft, The Netherlands.

${ }^{3}$ Department of Materials Science and Engineering, Delft University of Technology, Mekelweg 2, 2628 CD, Delft, The Netherlands

${ }^{4}$ Oak Ridge National Laboratory (ORNL), Materials Science and Technology Division, P.O. Box 2008, Oak Ridge, TN 37831-6136, USA
}

Keywords: Phase Transformations, bainitic steels, x-ray diffraction (XRD), threedimensional atom probe (3DAP)

\begin{abstract}
The aim of this work is to analyse the carbon distribution in austenite during isothermal bainite formation and the incomplete reaction phenomenon by means of X-ray diffraction analysis and atom-probe tomography in high silicon, manganese alloyed steels. Results will provide new evidence on the temporary cessation of bainitic ferrite formation at abnormally low transformation temperatures.
\end{abstract}




\section{Introduction}

The incomplete reaction phenomenon is defined as the temporary cessation of ferrite formation before the fraction of austenite transformed to ferrite, allowed by the lever rule in the absence of carbide precipitation at ferrite/austenite boundaries, is reached [1]. Over the last 25 years, this phenomenon has been an important issue on the definition of bainite transformation mechanisms. Different explanations for the incomplete reaction phenomenon have been reported in the literature. Bhadeshia and Edmonds [2] explained this phenomenon as a manifestation of the formation of essentially supersaturated bainitic ferrite so that the original bainitic ferrite retains much of the carbon content of the parent austenite. The partitioning of carbon into the residual austenite occurs immediately after formation. In that case, the bainite reaction is expected to cease as soon as the austenite carbon content reaches the value at which diffusionless transformation becomes thermodynamically impossible, since the free energies of the residual austenite becomes less than that of the bainitic ferrite of the same composition. The locus of points, on a temperature versus carbon concentration in austenite plot, where austenite and ferrite of the same chemical composition have the same free energy, is known as the $T_{o}$ curve. The $T_{o}^{\prime}$ curve is defined similarly but taking into account the stored energy of the ferrite due to the displacive mechanism of transformation (400 J mol${ }^{-1}$ ). The determination of the carbon content of the residual austenite at the termination of bainite reaction, and the experimental validation of $T_{o}^{\prime}$ curve, has been essential results to explain the incomplete reaction phenomenon [2-4]. Consistent with this theory, the characteristic flat top of the C-shaped time-temperature-transformation curve for the initiation of bainite transformation at a temperature $T_{h}$, which is the highest temperature at which ferrite can form by a displacive transformation, can be explained [5]. A very early explanation postulated that incomplete transformation is absent since the pearlite reaction replaces that of bainite in the incomplete reaction phenomenon range [6]. On the other hand, an alternative theory considers bainite as a non-lamellar two-phase 
aggregate of ferrite and carbide i.e. simply degenerate pearlite [7,8]. According to this definition, the upper limiting temperature of the bainite formation should be that of the eutectoid reaction $\left(A e_{1}\right)$, so the bainite start temperature, $T_{h}$, has no fundamental significance. Thus, the bainitic 'bay' is the highest temperature in the range where the coupled-solute drag effect slows down ferrite growth sufficiently so that growth can be increasingly supplemented by sympathetic nucleation, in agreement with the increasingly refined microstructure at 'sub-bay' temperatures $[9,10]$.

Recently $[11,12]$, the various theories proposed for the incomplete reaction phenomenon have been critically reviewed bringing back the discussion. According to Aaronson and coworkers, the currently most promising theories involve the cessation of growth induced by the coupled-solute drag effect, accentuated by the overlap of carbon diffusion fields associated with nearby ferrite crystals. Although they also admit that additional experimental-based isothermal transformation studies on the incomplete reaction phenomenon and bainite formation are needed, especially for Fe-C-Mn alloys with lower strength of coupled-solute drag effect upon ferrite formation, than that in Fe-C-Mo alloys widely reported.

Therefore, the aim of this work is to analyse carbon distribution in austenite during isothermal bainite formation, and the incomplete reaction phenomenon, by X-ray diffraction analysis and atom-probe tomography (APT) in medium carbon, high silicon, manganese alloyed steels. Silicon inhibits the formation of cementite in the progress of the bainite reaction, essential to study the incomplete reaction phenomenon. Likewise, the $T_{o}^{\prime}$ curve has been validated on a high carbon, high silicon bainitic steel that transforms to bainite at $200^{\circ} \mathrm{C}$, the temperature at which the diffusion of iron atoms is inconceivable during the course of the transformation [13]. These results will provide new evidence on the temporary cessation of bainitic ferrite formation at abnormally low transformation temperatures. 


\section{Experimental Procedure}

The chemical composition of the studied steels is given in Table 1. The medium carbon steels were supplied as $12 \mathrm{~mm}$ hot rolled strips, whereas the high carbon steel was supplied as as-cast ingots after homogenization at $1200^{\circ} \mathrm{C}$ for $48 \mathrm{~h}$. The alloys contain Si to prevent the precipitation of cementite during the bainite formation, $\mathrm{Mn}, \mathrm{Ni}, \mathrm{V}$ and $\mathrm{Cr}$ for hardenability, Mo to prevent temper embrittlement due to $\mathrm{P}$, and $\mathrm{Co}$ and $\mathrm{Al}$ to increase the bainitic ferrite fraction. Further details about their alloying design and manufacturing processes can be found elsewhere [14,15]. Dilatometric and metallographic analyses of the bainite isothermal transformation have allowed the study of the bainite transformation kinetics and the incomplete reaction phenomenon in the selected steels. An Adamel Lhomargy DT1000 high-resolution dilatometer has been used for that purpose [16]. Cylindrical dilatometric test pieces of $3 \mathrm{~mm}$ in diameter and $12 \mathrm{~mm}$ in length were austenitized at temperatures listed in Table 2 and then isothermally transformed at temperatures ranging from 150 to $475^{\circ} \mathrm{C}$ for different times before quenching. Prior austenite grain size (AGS) was revealed by means of the thermal etching technique [17] and measured by the linear intercept method, see also Table 2. Specimens were ground, polished and etched in a 2\% nital solution. Light Optical Microscopy (LOM) and Scanning Electron Microscopy (SEM) were used to examine the resulting microstructures. A JEOL JSM6500F Field Emission Scanning Electron Microscope operating at $7 \mathrm{kV}$ was employed for this purpose. The volume fraction of bainite was estimated by a systematic manual pointcounting procedure on LOM and SEM micrographs at low magnification. The volume fraction of the bainitic ferrite was estimated taking into account that the bainitic sheaves contain approximately $85 \%$ of bainitic ferrite and $15 \%$ of thin films of retained austenite [18].

The martensite start temperature $\left(\mathrm{M}_{\mathrm{S}}\right)$ was measured by dilatometry. Dilatometry specimens were austenised and then rapidly cooled. Each test was performed twice. The formation of 
martensite during cooling was detected by monitoring the fractional change in dilatation with temperature. Metallographic examination by LOM and SEM allowed determining the Widmanstätten ferrite $\left(\mathrm{W}_{\mathrm{S}}\right)$, bainite $\left(\mathrm{B}_{\mathrm{S}}\right)$, and lower bainite start temperatures $\left(\mathrm{LB}_{\mathrm{S}}\right)$.

Transmission Electron Microscopy (TEM) specimens were machined to $3 \mathrm{~mm}$ diameter rods and electropolished with a twin-jet electropolisher at room temperature in a mixture of $5 \%$ perchloric acid, $15 \%$ glycerol and $80 \%$ methanol at $40 \mathrm{~V}$ until perforation occurred. A JEOL JEM-2010 Transmission Electron Microscope was used to examine the microstructure at higher magnification.

Quantitative X-ray diffraction analysis was used to determine the volume fraction and carbon content of the retained austenite in the steels. After grinding and final polishing with $1 \mu \mathrm{m}$ diamond paste, the samples were etched to obtain an undeformed surface. A Siemens D 5000 X-ray diffractometer using unfiltered $\mathrm{Cu} K_{\alpha}$ radiation, at a scanning speed $(2 \theta)<$ 0.3 degree/min and operating at $40 \mathrm{kV}$ and $30 \mathrm{~mA}$ was used. The retained austenite carbon content was calculated from the lattice parameters obtained from the (200), (220) and (311) diffraction peaks according to ref. [19]. Lattice parameter estimation was performed by means of Cohen's [20] method together with some other extra considerations, described in detail in ref. [21], with the purpose of obtaining the most accurate values.

Atom probe tomography specimens were cut from bulk material and electropolished with the standard double layer and micropolishing methods [22]. Atom probe analyses were performed in the Oak Ridge National Laboratory (ORNL) local electrode atom probe. The introduction of this instrument has made dramatic, orders of magnitude improvements in the data acquisition rate and the size of the analyzed volume compared to previous types of three-dimensional atom probes. In this sense, results on the distribution of carbon in austenite at an atomic scale will confirm atom probe investigations performed in the 1980's essentials to explain the incomplete reaction phenomenon at that time [4]. The local electrode atom probe was operated with a specimen temperature of $60 \mathrm{~K}$, a pulse repetition rate of $200 \mathrm{kHz}$, and a pulse fraction of 0.2 . 
Thermodynamic calculations were performed with commercially available software in combination with the SGSOL-SGTE (Scientific Group Thermodata Europe database) Solution Database 3.0.

\section{Results and discussion}

Bainite transformation range and scale of microstructure: from micro to nano

The well known difference in carbide distribution between bainite formed at high and low temperatures, viz., intralath and interlath, respectively, appears to exist in a majority of steels and makes the classical nomenclature of upper and lower bainite useful, both in describing the microstructural appearance and in classifying the overall reaction mechanism. In upper bainite, the carbides precipitate from carbon-enriched residual austenite. Upper bainitic ferrite itself is free from precipitates. The precipitation of carbides in upper bainite is a secondary process, not essential to the mechanism of formation of bainitic ferrite except where any precipitation from austenite will deplete its carbon content, thereby promoting further transformation. Silicon can avoid the precipitation of cementite between the plates of bainitic ferrite, but it does not have a significant effect on the formation of cementite inside the ferrite plates [23]. Therefore, the formation of lower bainite is not inhibited in these steels. The precise role of intra-ferrite carbides in lower bainite formation is not clear. There are many observations that reveal that lower bainitic cementite nucleates and grows within supersaturated ferrite in a process identical to the tempering of martensite [24]. The slower diffusion associated with the reduced transformation temperature provides an opportunity for some of the carbon to precipitate in the supersaturated bainitic ferrite. A fine dispersion of plate-like carbides is then found inside the ferrite plates, with a single crystallographic variant within a given ferrite plate, although it is possible to observe more than one variant of carbide precipitation in a lower bainite sub-unit [24,25]. 
As an example, a sequence of micrographs for the different products of transformation in 0.3BAIN2 is shown in Fig. 1. A representative microstructure at relatively late stages of transformation at $275^{\circ} \mathrm{C}$, just below the $\mathrm{M}_{\mathrm{S}}$ temperature assessed by dilatometry, is shown in Fig. 1a. The microstructure is identified as self-tempered martensite $\left(\alpha_{s t}^{\prime}\right)$ and some retained austenite. An example of the lower bainite microstructure after isothermal transformation at $325^{\circ} \mathrm{C}$ is shown in Fig. 1b. Particles of cementite are easily identified inside the bainitic ferrite plates. In contrast, a typical upper bainitic microstructure, where it is possible to observe the subunits of bainitic ferrite with retained austenite among them, is displayed in Fig. 1c. Concerning the morphology of the austenite remaining after partial transformation to bainite, it is possible to distinguish between the blocky morphology of austenite $\left(\gamma_{b}\right)$ located between the sheaves of bainite and the films of austenite $\left(\gamma_{\mathrm{f}}\right)$ which are retained between the subunits within a given sheaf of bainite. Finally, when the isothermal temperature is increased to $450^{\circ} \mathrm{C}$, ferrite having a serrated morphology is identified as Widmanstätten ferrite $\left(\alpha_{\mathrm{w}}\right)$, Fig. 1d, that without question can not be confused with allotriomorphic ferrite $(\alpha)$, as the one easily revealed after transformation at $625^{\circ} \mathrm{C}$, Fig. $1 \mathrm{e}$. Equivalent analyses were performed in the other steels and the experimental values of the $\mathrm{W}_{\mathrm{S}}, \mathrm{B}_{\mathrm{S}}, \mathrm{LB}_{\mathrm{S}}$ and $\mathrm{M}_{\mathrm{S}}$ temperatures are shown in Table 3. It is necessary to highlight the fact that there is a small interval of temperatures, above the $\mathrm{W}_{\mathrm{S}}$ and the lowest temperature at which allotriomorphic ferrite and pearlite are identified, where no decomposition of austenite was observed in the time scale of the experiments. This is a clear indication of the separation between those phases formed by a displacive mechanism, (martensite, bainite and Widmanstätten ferrite) and those controlled by a reconstructive mechanism (allotriomorphic ferrite and pearlite).

Thermodynamic conditions that explain the differences between Widmanstätten ferrite and bainite were reported by Bhadeshia [26]. It was shown that the nucleus is identical for Widmanstätten and bainitic ferrite, and the difference arises during growth. If diffusionless growth cannot be sustained at $T_{h}$, then the nucleus evolves into Widmanstätten ferrite, so $T_{h}$ 
is identified as $\mathrm{W}_{\mathrm{S}}$. Further undercooling is necessary before bainite can be stimulated. But, if the driving force at $T_{h}$ is enough to account for diffusionless growth, then $T_{h}=\mathrm{B}_{\mathrm{S}}$ and Widmanstätten ferrite does not form. Hence only two types of ferrite growth are considered: one which is carbon diffusion controlled, with equilibrium partitioning of carbon, and the other involving a full carbon supersaturation, a growth which is, in essence, martensitic.

Widmanstätten or bainitic ferrite will thus form when the following two conditions are satisfied

Nucleation $\quad \Delta G_{M a x}<G_{N} \quad$ and

$$
\begin{aligned}
& \text { Growth } \quad \Delta G^{\gamma \rightarrow(\gamma+\alpha)_{p}}<-G_{S W} \text {, } \\
& \Delta G^{\gamma \rightarrow \alpha}<-G_{S B}
\end{aligned}
$$

where $G_{S W}$ and $G_{S B}$ are the stored energies per mole of Widmanstätten and bainitic ferrite with values of 50 and $400 \mathrm{~J} / \mathrm{mol}$, respectively; $\Delta G^{\gamma \rightarrow(\gamma+\alpha)_{p}}$ is the free energy change accompanying transformation of austenite to a mixture of austenite and ferrite under paraequilibrium conditions; $\Delta G^{\gamma \rightarrow \alpha}$ accounts for the free energy change when austenite transforms to ferrite without a change in chemical composition; $G_{N}$ is the minimum free energy change necessary to achieve a perceptible nucleation rate for bainitic or Widmanstätten ferrite; and $\Delta G_{M a x}$ is the maximum possible free energy change for nucleation. A graphical solution for the calculation of the $\mathrm{B}_{\mathrm{S}}$ and $\mathrm{W}_{\mathrm{S}}$ temperatures using thermodynamic theory is reported elsewhere [26] and is shown for 0.3BAIN2 steel in Fig. 2. Two well defined regions where Widmanstätten and bainitic ferrite may form in 0.3BAIN2 steel are predicted, in agreement with metallographic results.

The thermodynamic model described above was used to produce the finest possible bainitic microstructure by transformation at the lowest possible temperature [13]. The carbon 
concentration of NANOBAIN steel (Table 1) was mainly selected to decrease the $\mathrm{B}_{\mathrm{s}}$ temperature as much as possible and to make austenite stronger with the aim of obtaining extremely thin platelets of bainite. In the absence of precipitation at ferrite/austenite boundaries, the thickness of bainite plates depends primarily on the strength of the austenite at the transformation temperature, and the chemical free energy change accompanying transformation [27]. This applies specifically when the shape deformation causes plastic strain in the adjacent austenite. Strong austenite, or a large driving force, results in finer plates. The former because there is a larger resistance to interface motion and the latter because an increased nucleation rate leads to microstructural refinement.

TEM micrographs of NANOBAIN transformed at $200^{\circ} \mathrm{C}$ for 10 days are presented in Fig. 3. Some of the plates of bainite are thin and long, resulting in a fine-scale structure consisting of an intimate mixture of austenite and bainitic ferrite. Dislocation debris is evident close to an austenite-bainitic ferrite interface in Fig. 3b. The relatively high dislocation density associated with bainitic ferrite is often attributed to the fact that the shape deformation accompanying the displacive transformation is accommodated at least partially by plastic relaxation [28]. It is possible, using X-ray diffraction analysis, to measure the non-uniform strains present in ferrite and to relate these values to the dislocation density in the bainitic ferrite [29]. Moreover, the true bainitic ferrite plate thickness was determined from TEM micrographs by measuring the mean linear intercept in a direction normal to the plate length [30]. The dislocation density and the corresponding bainitic ferrite thickness as function of transformation temperature is shown in Fig. 4. It is clear that there is a strong correlation between both, confirming that plastic strain in the adjacent austenite plays an important role on the resultant scale of the microstructure. The observed refinement is mainly a consequence of the effect of high carbon content and the low transformation temperature on increasing the strength of the austenite in NANOBAIN steel.

Remarkably, the micrographs shown in Fig. 3 and extensive TEM examination of this novel microstructure failed to reveal carbide particles inside the bainitic ferrite leading to the 
doubtful hypothesis that upper bainite was formed at these extremely low temperatures. However, after a large and equivalent set of accumulated atom probe results, the presence of cementite was confirmed as the lower bainite carbide in NANOBAIN steel. An example of a carbon atom map of a carbide particle precipitated inside bainitic ferrite for a sample transformed at $200^{\circ} \mathrm{C}$ for 10 days is shown in Fig. 5. Despite the apparent lower average carbon concentration of the carbide (20 \pm 4 at.\%), the measured carbon level allows the type of carbide precipitated inside bainitic ferrite to be identified as cementite (i.e. 25 at.\% for cementite versus 30 at.\% for $\varepsilon$-carbide). The absence of $\varepsilon$-carbide as the initial carbide of the precipitation sequence in lower bainite formation is explained in terms of carbon trapped at dislocations by the tempering theory of Kalish and Cohen suggested [31]. They showed that it is energetically favourable for carbon atoms to remain segregated at dislocations compared with their presence in the $\varepsilon$-carbide lattice. Hence, if the dislocation density is high, as it is for bainite, sufficient carbon can be captured by dislocations so $\varepsilon$-carbide precipitation is eliminated in the tempering sequence. In such a case, cementite precipitation occurs directly. Atom probe tomography results reported elsewhere [32] revealed that a substantial quantity of carbon $(7.4$ at.\% C) was trapped at dislocations in the vicinity of the ferrite/austenite interface in NANOBAIN steel.

Approaching $T_{o}^{\prime}$ curve during bainite formation

The evolution of the carbon content in austenite, as determined from X-ray diffraction analysis, during transformation at $300^{\circ} \mathrm{C}$ in NANOBAIN steel is shown in Fig. 6. As bainitic ferrite formation progresses, austenite is gradually enriched in carbon from the overall carbon content $\left(\mathrm{X}_{\mathrm{o}}\right)$ to that given by the $T_{o}$ curve. Similarly, the carbon content of the austenite at the termination of phase transformation for different temperatures in all studied steels is shown in Fig. 7. The calculated values for $T_{o}^{\prime}$ and paraequilibrium $A e_{3}^{\prime}$ phase boundaries are also plotted. Likewise, the same type of calculation, but not 
considering the stored energies of the related phases, are presented as $T_{o}$ and $A e_{3}$. The measured concentrations in austenite at temperatures below the $\mathrm{B}_{\mathrm{S}}$ temperature (See Table 3 and Fig. 7) lie closer to the $T_{o}^{\prime}$ or $T_{o}$ value boundaries and far from the paraequilibrium phase boundaries ( $A e_{3}$ and $A e_{3}^{\prime}$ lines) for all the studied steels. The results are consistent with a mechanism in which the bainite grows without diffusion, but with excess carbon partitioning into the austenite soon after transformation. The reaction is said to be incomplete since transformation stops before the phases achieve their equilibrium compositions.

In general, the partitioning of carbon into the austenite and the precipitation of carbides from a supersaturated matrix as in lower bainite (carbide precipitation at the interface as in upper bainite is not applicable here because of the high silicon content in the studied steels) are competitive processes, the relative rates depending on alloy chemistry and transformation temperature. The incomplete reaction phenomenon is not well pronounced in steels where cementite precipitation dominates, as in plain carbon steels [2]. In this work, no different trend is observed in the carbon content of the austenite at temperatures below $\mathrm{LB}_{\mathrm{S}}$ temperature (Fig. 7), suggesting that cementite precipitation is not a dominant process during the bainite reaction in the studied steels.

In contrast, the measured carbon content of retained austenite at temperatures above the $\mathrm{B}_{\mathrm{S}}$ temperature in 0.3BAIN1 - 3 steels corresponds to that given by the $A e_{3}$ and $A e_{3}^{\prime}$ lines. The presence of Widmanstätten ferrite and the absence of precipitation in the microstructure formed at the highest temperatures in these steels (see example in Fig. 1d) suggests that this trend is consistent with the difference between the growth mechanisms for Widmanstätten and bainitic ferrite formation, the former involving carbon diffusion control, with equilibrium partitioning of carbon, and the latter involving a full carbon supersaturation, a growth which is, in essence, martensitic [26]. 
A comparison of the carbon concentration in austenite at the termination of bainite transformation for different temperatures in two steels with different average carbon content (0.2BAIN and 0.3BAIN4 steels) is presented in Fig. 8. It is clear that there is no dependence on the average carbon content. This result is consistent with $T_{o}^{\prime}$ calculations, as both steels exhibit the same $T_{o}^{\prime}$ curve. By contrast, Quidort et al [33] observed a strong influence of the carbon content of the steel on the carbon concentration of the austenite at bainite stasis (i.e., when the bainite transformation ends) in three high silicon steels with an average carbon content ranging between 0.12 and $0.43 \mathrm{wt}-\%$. They proposed that the plastic resistance of austenite is responsible for the incomplete transformation and they evaluated the implications of the process of plastic accommodation in the austenite matrix, considering plastic deformation as an additional source of Gibbs energy dissipation during bainite transformation. Again, the results in Fig. 8 confirm that the incomplete reaction phenomenon is a manifestation of the formation of bainitic ferrite with a full supersaturation of carbon followed by carbon partitioning between bainitic ferrite and austenite. The driving force for the formation of new plates decreases as the carbon concentration in the untransformed austenite approaches the $T_{o}^{\prime}$ composition, at which the free energy of ferrite and austenite phases of the same composition become identical [2,5].

\section{Heterogeneous distribution of carbon in austenite}

Experimental results shown in Fig. 7 indicate that in certain cases, the measured carbon concentrations exceed the $T_{o}$ concentration. This is a consequence of the fact that the austenite films entrapped between neighbouring sub-units of bainitic ferrite have a higher carbon content than the blocks of residual austenite located between the sheaves of bainite, which may transform to martensite during subsequent quench [2]. This inhomogeneous distribution of carbon would allow the transformation to proceed to an extent somewhat 
greater than that allowed by the thermodynamic conditions based on an uniform carbon assumption.

Shelf et al. [34] proved quantitatively the existence of non-uniform distributions of carbon in the retained austenite by measuring austenite lattice spacing from TEM lattice fringes. Atom probe tomography can directly determine the distribution of carbon in austenite. Carbon atom maps obtained from $0.3 \mathrm{BAIN} 1$ steel isothermally transformed at $325^{\circ} \mathrm{C}$ for $1350 \mathrm{~s}$ are shown in Figs. 9a and 9b. The distribution of carbon atoms in the analysis volume is not uniform and carbon-enriched and carbon-depleted regions are clearly distinguishable. As no crystallographic information is available, the carbon-enriched regions of the atom maps are assumed to represent a region of austenite as its carbon content is higher than the average value of 1.32 at.\% and the low carbon $(<1$ at.\%) regions indicates the ferrite phase. This figure shows two examples of an austenite-ferrite interface for two different sizes of austenite regions. The corresponding carbon concentration profiles are also presented in Figs. 9c and 9d for the specimens shown in Figs. 9a and 9b, respectively. The average carbon content in the 80-nm-thick austenite region of the carbon atom map in Fig. $9 \mathrm{a}$ is $6.4 \pm 1.8$ at.\% $\mathrm{C}$, similar to the corresponding X-ray $(6.0 \pm 0.3$ at.\% $\mathrm{C})$ and $T_{o}(5.5$ at.\%) values, whereas the average carbon content in the $3.5 \mathrm{~nm}$ thick austenite film of the carbon atom map in Fig. $9 \mathrm{~b}$ is $9.8 \pm 0.4$ at.\% C, well beyond the $T_{o}$ (5.5 at.\%) curve, but less than the paraequilibrium $\mathrm{Ae}_{3}$ boundary (17.3 at.\%). Atom probe results confirm that finer austenite films accumulate higher amounts of carbon during bainite formation. The local carbon content in blocky austenite must be lower than the average given by X-ray diffraction analysis; unfortunately, coarse features observed in SEM, such as blocky austenite (Fig. 1c), are not readily observed in APT, without special lift-out specimen preparation methods, due to the more limited volume of analysis. 


\section{Summary}

Experimental results on the temporary cessation of bainitic ferrite formation in medium and high carbon, high silicon, manganese alloyed steels confirm that the incomplete reaction phenomenon can be explained in terms of the diffusionless growth of bainite sub-units. The partitioning of carbon into the residual austenite occurs immediately after formation. The bainite reaction ceases as soon as the austenite carbon content reaches the $T_{o}$ value. Results provide new evidence on the explanation for the incomplete reaction phenomenon at abnormally low transformation temperatures. Moreover, direct quantitative proof for the non-uniform distribution of carbon in the retained austenite has been provided by local electrode atom probe tomography. These results are complementary to former experimental evidence using austenite lattice spacing from TEM lattice fringes.

\section{Acknowledgement}

The authors acknowledge the support of Spanish Ministerio de Ciencia y Tecnología Plan Nacional de I+D+I (2004-2007), funding this research under the contracts PTR95-0995 and MAT2007-63873. Research at the Oak Ridge National Laboratory SHaRE User Facility was sponsored by the Scientific User Facilities Division, Office of Basic Energy Sciences, U.S. Department of Energy.

\section{References}

[1] Hehemann RF, Kinsman KR. Aaronson HI. Metall Trans 1972; 3: 1077.

[2] Bhadeshia HKDH, Edmonds DV. Acta Metall 1980; 28: 1265.

[3] Bhadeshia HKDH, Edmonds DV. Metall. Trans 1979; 10A: 895. 
[4] Bhadeshia H KDH, Waugh AR. Acta Metall 1982; 30: 775.

[5] Zener C. Trans AIME 1946; 167: 50.

[6] Hehemann RF Troiano AR. Met Progr 1956; 70: 97.

[7] Aaronson HI. The decomposition of austenite by diffusional processes. Zackary VF Aaronson HI, editors. New York: Interscience Publishers, 1962. p. 387.

[8] Aaronson HI. The mechanism of phase transformations in crystalline solids. London: The Institute of Metals, 1969. p. 270.

[9] Aaronson HI, Spanos G, Reynolds Jr WT. Scr Mater 2002; 47: 139.

[10] Reynolds Jr WT, Li FZ, Shui CK, Aaronson HI. Metall Trans 1990; 21A: 1433.

[11] Aaronson HI, Reynolds Jr WT, Purdy GR. Metall Mater Trans 2004; 35A: 1187.

[12] Aaronson HI, Reynolds Jr WT, Purdy GR. Metall Mater Trans 2006; 37A: 1731.

[13] Caballero FG, Bhadeshia HKDH. Current Opinion in Solid State and Materials Science 2004; 8, 251.

[14] Caballero FG, Santofimia MJ, Capdevila C, García-Mateo C, García de Andrés C. ISIJ Inter 2006; 46: 1479.

[15] García-Mateo C, Caballero FG, Bhadeshia HKDH. ISIJ Inter 2003; 43: 1821.

[16] García de Andrés C, Caballero FG, Capdevila C, Álvarez LF. Materials Characterization 2002; 48: 101.

[17] García de Andrés C, Caballero FG, Capdevila C, San Martín D. Materials Characterization 2003; 49: 121.

[18] Bhadeshia HKDH, Edmonds DV. Metal Sci 1983; 17: 411.

[19] Dyson DJ, Holmes B. J. Iron Steel Inst. 1970; 208: 469.

[20] Cullity BD, Stock SR. Elements of X-ray diffraction. $3^{\text {rd }}$ Edition. New York: Prentice Hall, 2001.

[21] García-Mateo C, Peet M, Caballero FG, Bhadeshia HKDH. Mater Sci Technol 2004; 20: 814 . 
[22] Miller MK. Atom probe tomography. New York (NY): Kluwer Academic/Plenum Press, 2000, p. 28.

[23] Kozeschnik E, Bhadeshia HKDH. Mater Sci Technol 2008; 24: 343.

[24] Bhadeshia HKDH. Acta Metall 1980; 28: 1103.

[25] Chang LC. Mat Sci Eng A 2004; $368: 175$.

[26] Bhadeshia HKDH. Acta Metall 1981; 29: 1117.

[27] Singh SB, Bhadeshia HKDH. Mater Sci Eng 1998; 245A: 72.

[28] Bhadeshia HKDH, Christian JW. Metall Trans 1990; 21A: 767

[29] Garcia-Mateo C, Caballero FG. ISIJ Int 2005; 45: 1736.

[30] García-Mateo C, Caballero FG, Bhadeshia HKDH. ISIJ Int 2003; 43: 1821.

[31] Kalish D, Cohen M. Mater Sci Eng 1970; 6: 156.

[32] Caballero FG, Miller MK, Babu SS, Garcia-Mateo C. Acta Mater 2007; 55: 381.

[33] Quidort D, Bouaziz O, Brechet Y. Austenite formation and decomposition. Buddy Damm E, Merwin MJ, editors. Warendale (PA): TMS, 2003. p. 15.

[34] Self P, Bhadeshia HKDH, Stobbs WM. Ultramicroscopy 1981; 6: 29. 


\section{Figure Captions}

Figure 1. Optical and scanning electron micrographs of 0.3BAIN2 steel: (a) $7200 \mathrm{~s}$ at $275^{\circ} \mathrm{C}$; (b) $1800 \mathrm{~s}$ at $325^{\circ} \mathrm{C}$; (c) $1800 \mathrm{~s}$ at $400^{\circ} \mathrm{C}$; (d) $1800 \mathrm{~s}$ at $450^{\circ} \mathrm{C}$; and (e) $7200 \mathrm{~s}$ at $625^{\circ} \mathrm{C} . \alpha^{\prime}$ is martensite, $\alpha_{\mathrm{st}}{ }^{\prime}$ is self-tempered martensite; $\alpha_{\mathrm{lb}}$ is lower bainitic ferrite; $\alpha_{\mathrm{ub}}$ is upper bainitic ferrite; $\gamma_{\mathrm{f}}$ is austenite films; $\gamma_{\mathrm{b}}$ is blocky austenite; $\alpha_{\mathrm{w}}$ is Widmanstätten ferrite; $\alpha$ is allotriomorphic ferrite; and $\mathrm{P}$ is pearlite.

Figure 2. Graphical solution for the determination of $\mathrm{B}_{\mathrm{S}}$ and $\mathrm{W}_{\mathrm{S}}$ in $0.3 \mathrm{BAIN} 2$ steel.

Figure 3. Transmission electron micrographs of (a) microstructure obtained at $200^{\circ} \mathrm{C}$ for 10 days in NANOBAIN steel; (b) dislocation debris close to austenite-bainitic ferrite interface. $\alpha_{\mathrm{b}}$ is bainitic ferrite; and $\gamma_{\mathrm{f}}$ is austenite films.

Figure 4. Dislocation density in bainitic ferrite and bainitic ferrite plate thickness in NANOBAIN steel after isothermal transformation at different temperatures ensuring that bainitic transformation was finished.

Figure 5.- (a) Carbon atom map and (b) carbon concentration profile showing cementite particle precipitated inside bainitic ferrite in NANOBAIN steel transformed at $200^{\circ} \mathrm{C}$ for 10 days. $\alpha_{b}$ is bainitic ferrite and $\theta$ is cementite.

Figure 6.- Carbon content in austenite and bainitic ferrite fraction of the microstructure obtained in NANOBAIN steel by isothermal transformation at $300^{\circ} \mathrm{C}$ for 4 to $19 \mathrm{~h}$; $\mathrm{X}_{\mathrm{o}}$ represents the overall carbon content of the steel. $T_{o}$ and the para-equilibrium $\mathrm{A}_{3}$ curves 
were calculated for the studied steel using commercially available software in combination with the SGSOL-SGTE Solution Database 3.0.

Figure 7.- Calculated phase boundaries for all steel grades together with X-ray experimental data representing the carbon concentration of the austenite which is left untransformed after cessation of the bainite/Widmanstätten reaction.

Figure 8.- Influence of average carbon content on incomplete reaction phenomenon.

Figure 9.- (a), (b) Carbon atom maps; and (c), (d) corresponding concentration profiles across austenite-ferrite interface in $0.3 \mathrm{BAIN} 1$ steel transformed at $325^{\circ} \mathrm{C}$ for $1350 \mathrm{~s} . \alpha_{\mathrm{b}}$ is bainitic ferrite and $\gamma$ is austenite. 
Table 1: Chemical composition of studied steels, wt- $\%$

\begin{tabular}{|c|c|c|c|c|c|c|c|c|c|}
\hline Steel & $\mathrm{C}$ & $\mathrm{Si}$ & $\mathrm{Mn}$ & $\mathrm{Ni}$ & $\mathrm{Cr}$ & Mo & $\mathrm{Co}$ & $\mathrm{Al}$ & $\mathrm{V}$ \\
\hline $0.2 \mathrm{BAIN}$ & 0.21 & 1.46 & 1.56 & --- & 1.49 & 0.25 & --- & --- & --- \\
\hline 0.3BAIN1 & 0.29 & 1.48 & 2.06 & & 0.43 & 0.27 & & & \\
\hline (at.\%) & $(1.32)$ & $(2.87)$ & (2.04) & --- & $(0.45)$ & $(0.15)$ & --- & --- & --- \\
\hline $0.3 \mathrm{BAIN} 2$ & 0.29 & 1.45 & 1.97 & --- & 0.95 & 0.26 & 0.67 & --- & --- \\
\hline 0.3BAIN3 & 0.31 & 1.40 & 1.97 & 1.7 & 1.41 & 0.26 & 1.13 & 1.01 & --- \\
\hline $0.3 \mathrm{BAIN} 4$ & 0.29 & 1.49 & 1.56 & --- & 1.47 & 0.25 & --- & --- & --- \\
\hline NANOBAIN & 0.98 & 1.46 & 1.89 & & 1.26 & 0.26 & & & 0.09 \\
\hline (at.\%) & $(4.34)$ & $(2.76)$ & (1.82) & --- & $(1.28)$ & $(0.14)$ & --- & --- & (0.09) \\
\hline
\end{tabular}


Table 2: Austenitisation conditions and corresponding prior austenite grain size (PAGS) of studied steels

\begin{tabular}{llc}
\hline Steel & Austenitisation Conditions & PAGS, $\mu \mathrm{m}$ \\
\hline $0.2 \mathrm{BAIN}$ & $950^{\circ} \mathrm{C}$ for $300 \mathrm{~s}$ & $12 \pm 3$ \\
\hline $0.3 \mathrm{BAIN} 1$ & $925^{\circ} \mathrm{C}$ for $300 \mathrm{~s}$ & $12 \pm 5$ \\
$0.3 \mathrm{BAIN} 2$ & $925^{\circ} \mathrm{C}$ for $300 \mathrm{~s}$ & $14 \pm 5$ \\
0.3 BAIN3 & $925^{\circ} \mathrm{C}$ for $300 \mathrm{~s}$ & $15 \pm 7$ \\
$0.3 \mathrm{BAIN} 4$ & $900^{\circ} \mathrm{C}$ for $300 \mathrm{~s}$ & $12 \pm 3$ \\
\hline NANOBAIN & $1000^{\circ} \mathrm{C}$ for $900 \mathrm{~s}$ & $49 \pm 3$ \\
\hline
\end{tabular}


Table 3: Experimental transformation temperatures in ${ }^{\circ} \mathrm{C}$ of studied steels

\begin{tabular}{lllcc}
\hline Steel & $\mathrm{W}_{\mathrm{S}},{ }^{\circ} \mathrm{C}$ & $\mathrm{B}_{\mathrm{S}},{ }^{\circ} \mathrm{C}$ & $\mathrm{LB}_{\mathrm{S}},{ }^{\circ} \mathrm{C}$ & $\mathrm{M}_{\mathrm{S}},{ }^{\circ} \mathrm{C}$ \\
\hline 0.2 BAIN & --- & $500 \pm 12$ & $375 \pm 12$ & $368 \pm 2$ \\
\hline 0.3 BAIN1 & $525 \pm 12$ & $450 \pm 12$ & $350 \pm 12$ & $299 \pm 8$ \\
0.3 BAIN2 & $500 \pm 12$ & $400 \pm 12$ & $350 \pm 12$ & $296 \pm 7$ \\
0.3 BAIN3 & $450 \pm 12$ & $400 \pm 12$ & $350 \pm 12$ & $316 \pm 10$ \\
0.3 BAIN4 & --- & $450 \pm 12$ & $350 \pm 12$ & $322 \pm 19$ \\
\hline NANOBAIN & --- & $335 \pm 12$ & $335 \pm 12$ & $123 \pm 4$ \\
\hline
\end{tabular}




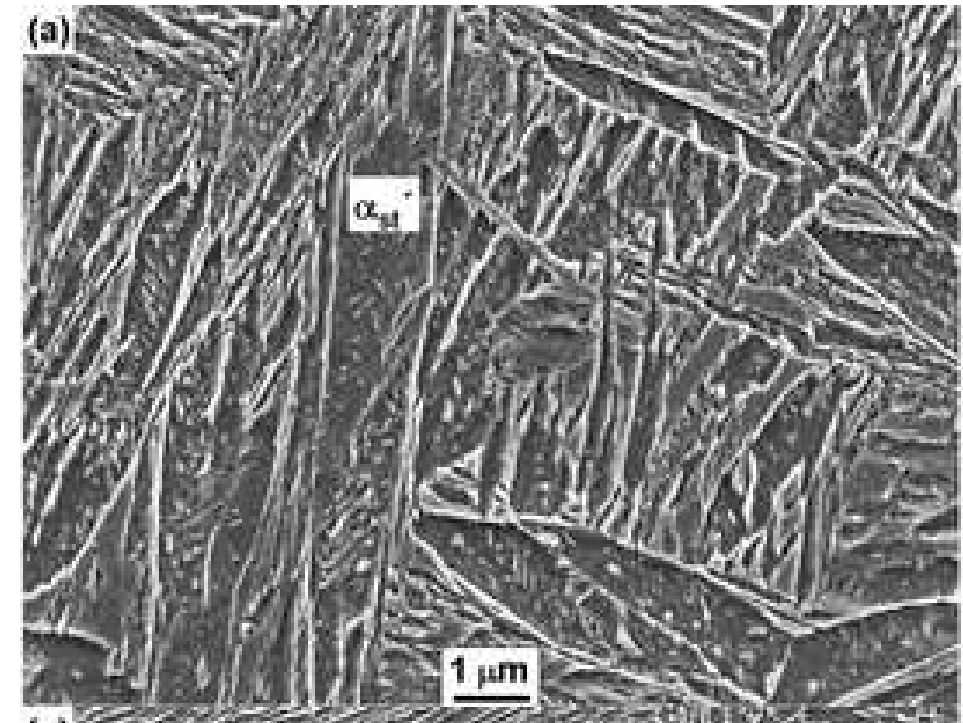

(c) 5 (d)

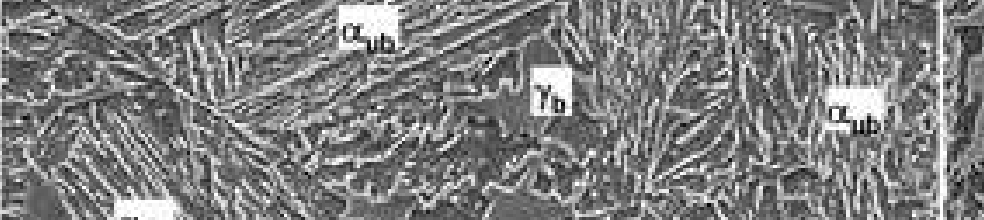

A

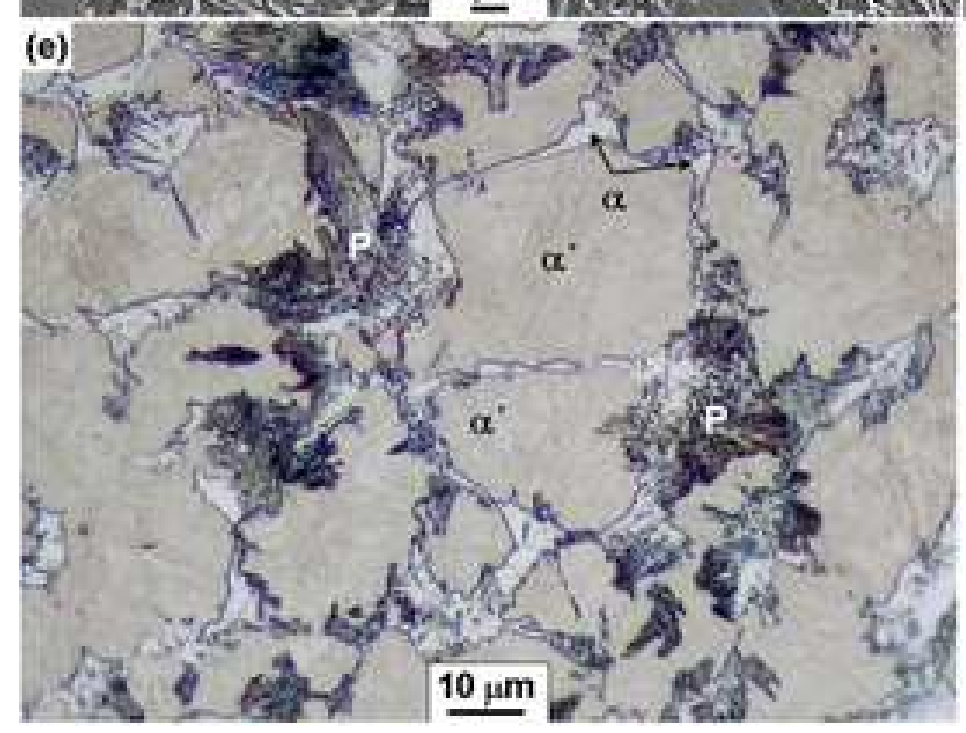


Temperature/ ${ }^{\circ} \mathrm{C}$

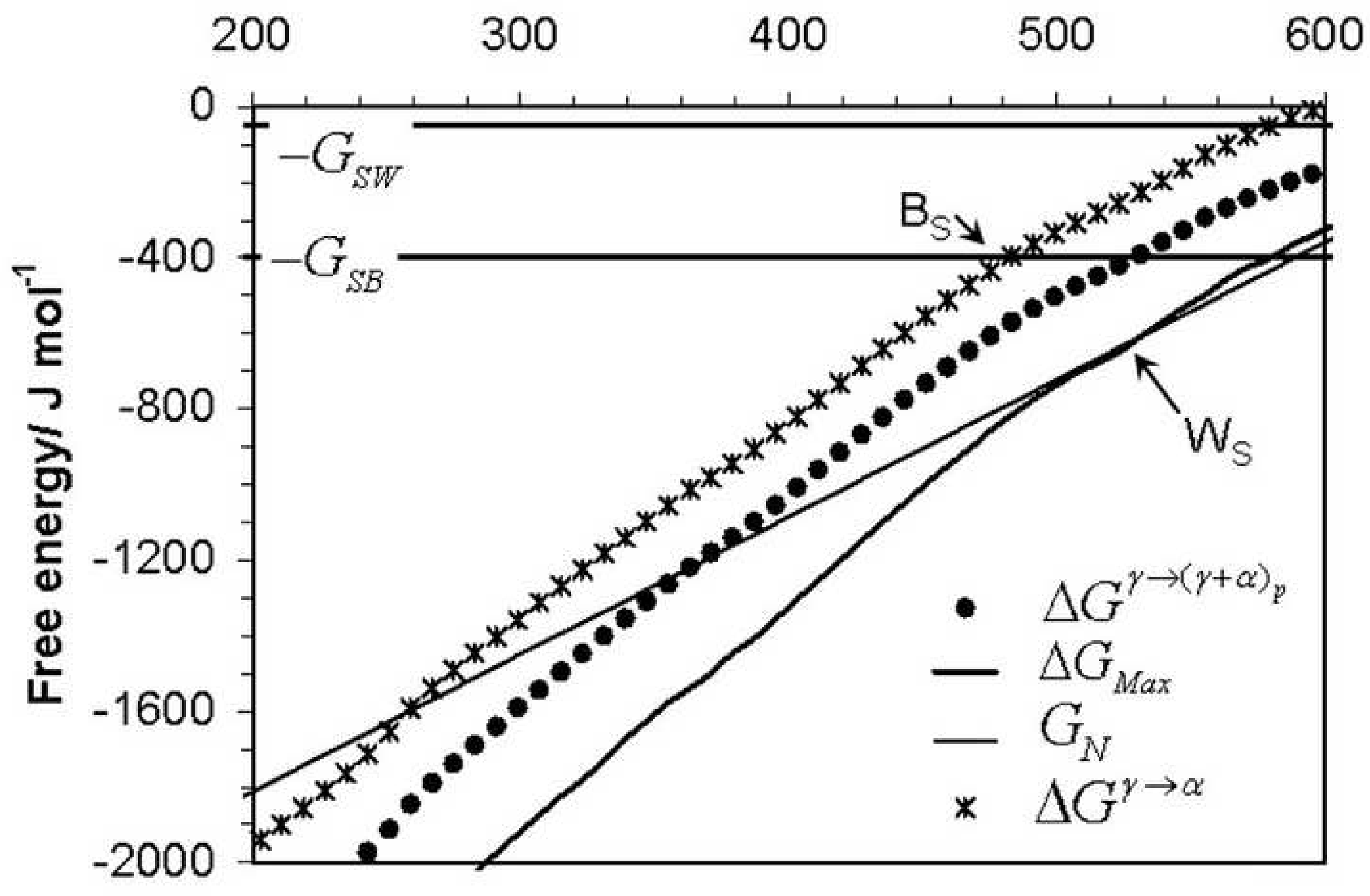



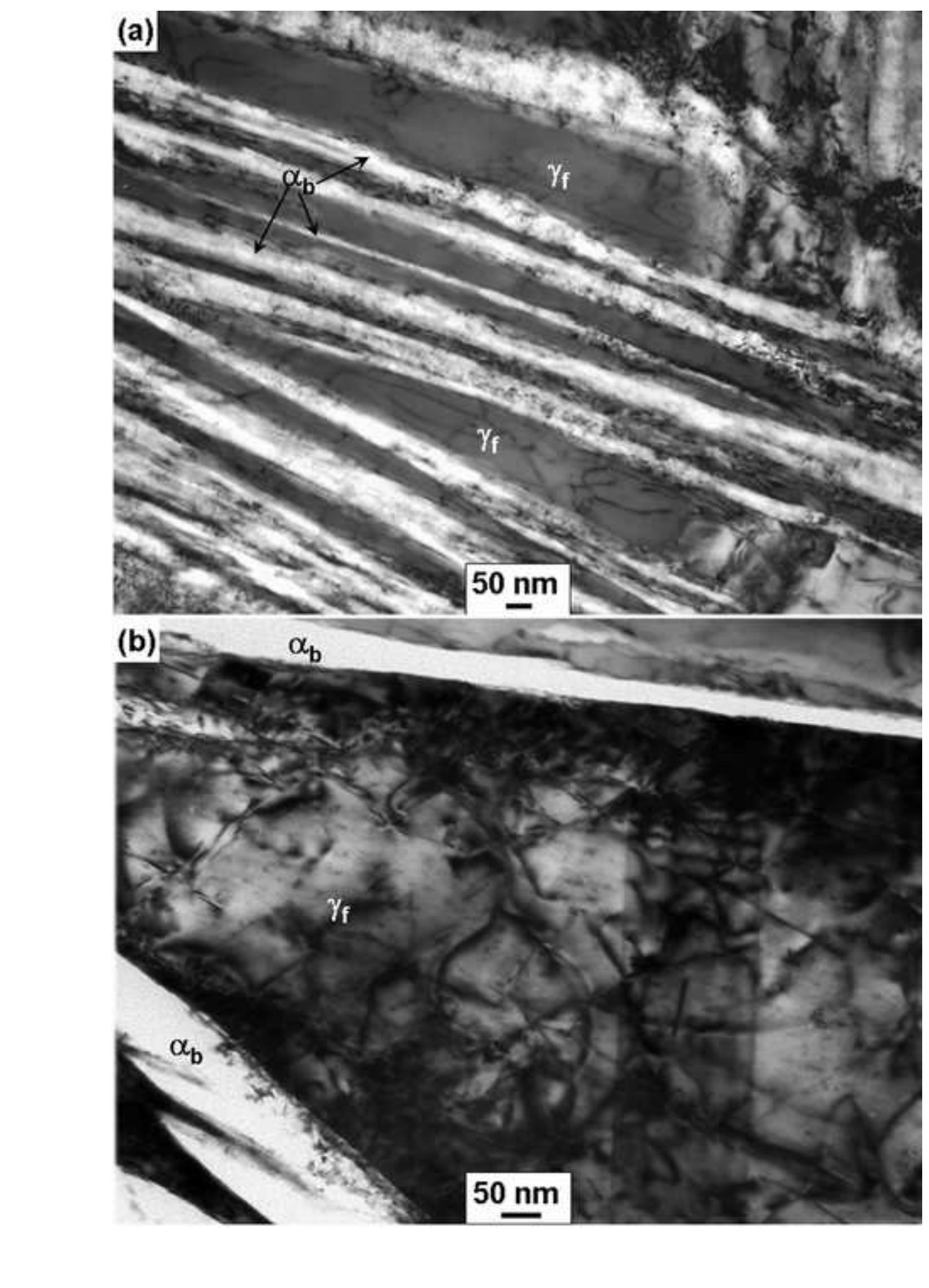

Figure 3

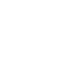

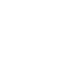


$\checkmark$-Dislocation density $\triangle$ Bainitic ferrite thickness

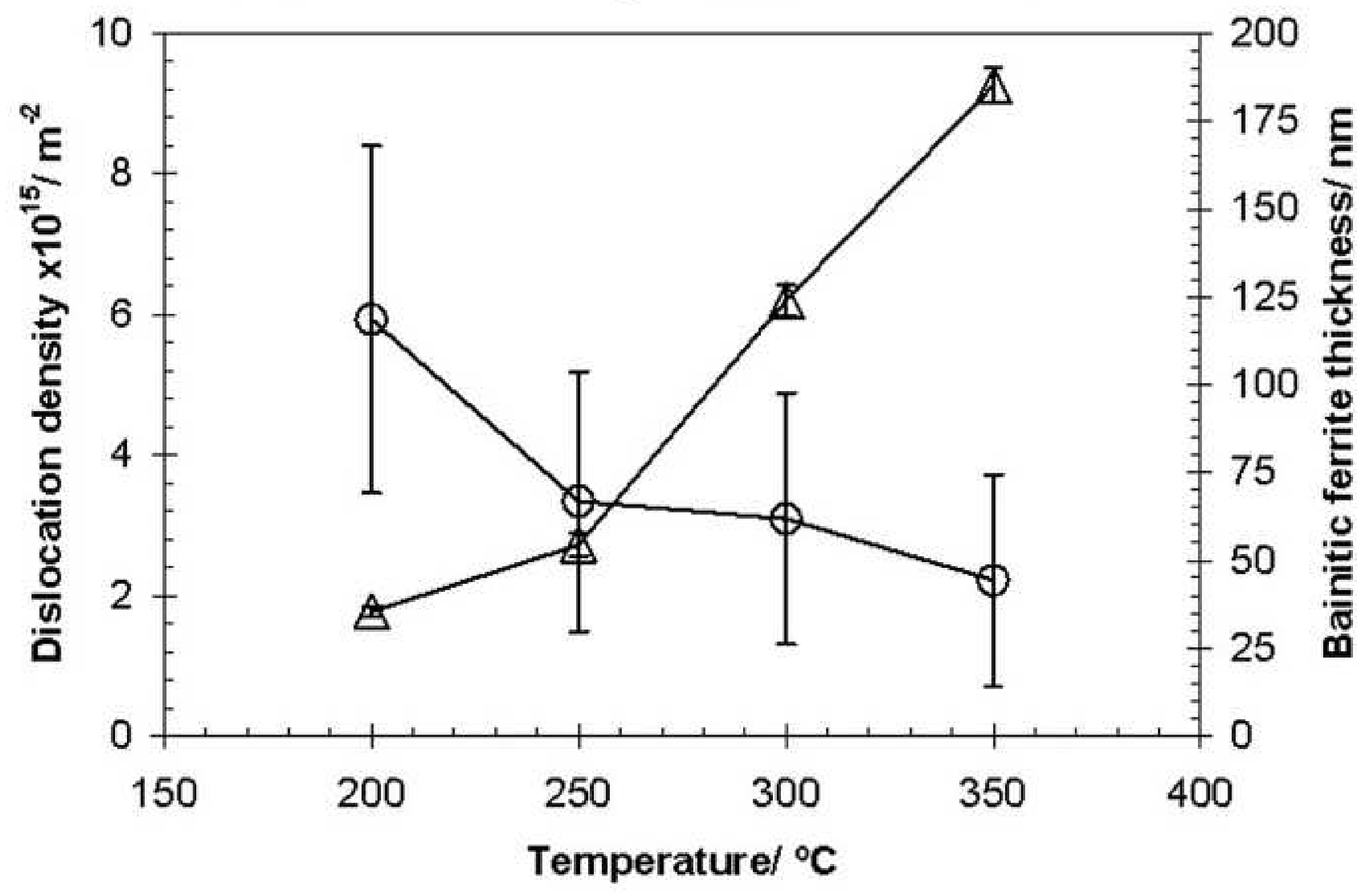


(a)

(b)

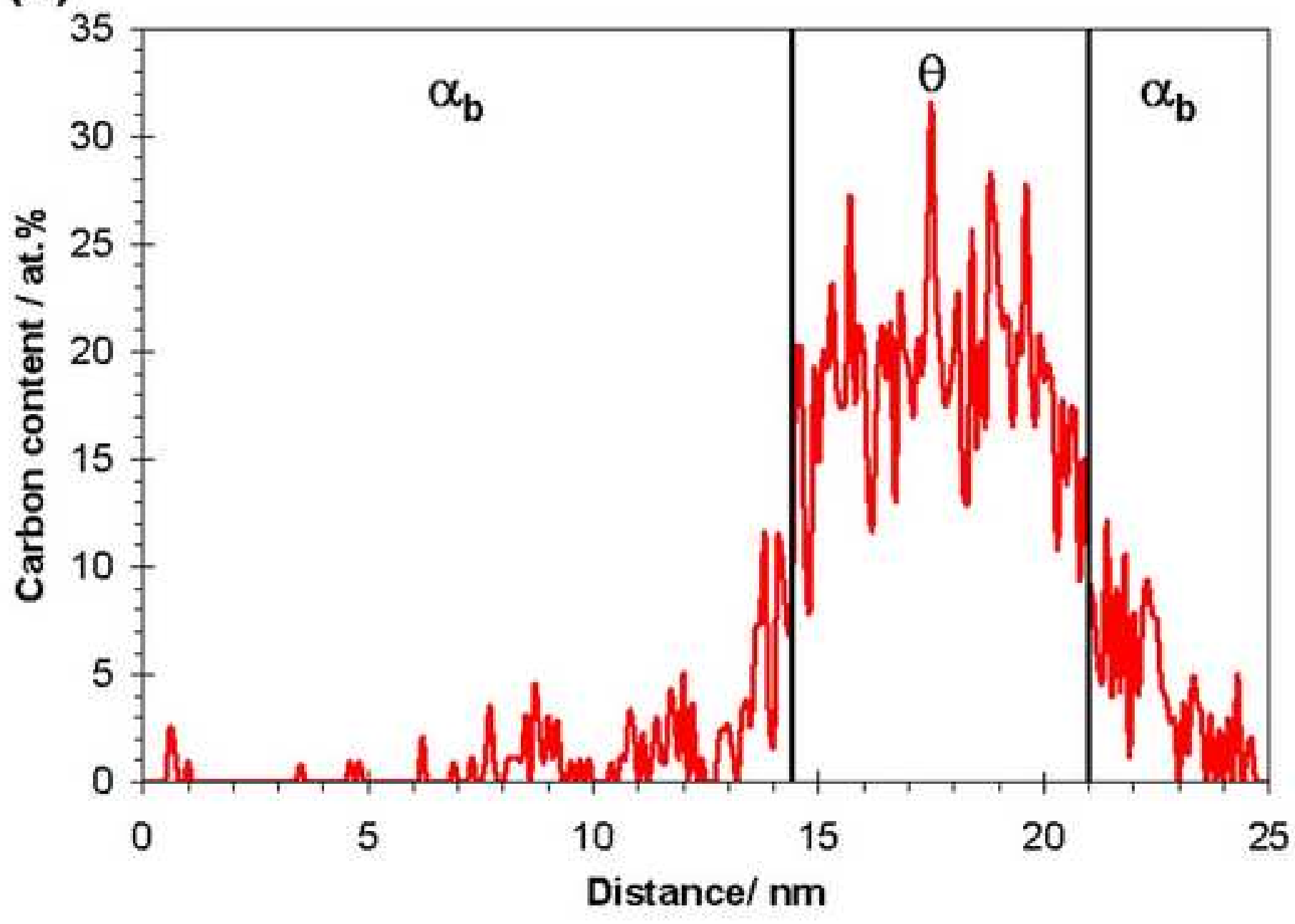

$5 \mathrm{~nm}$

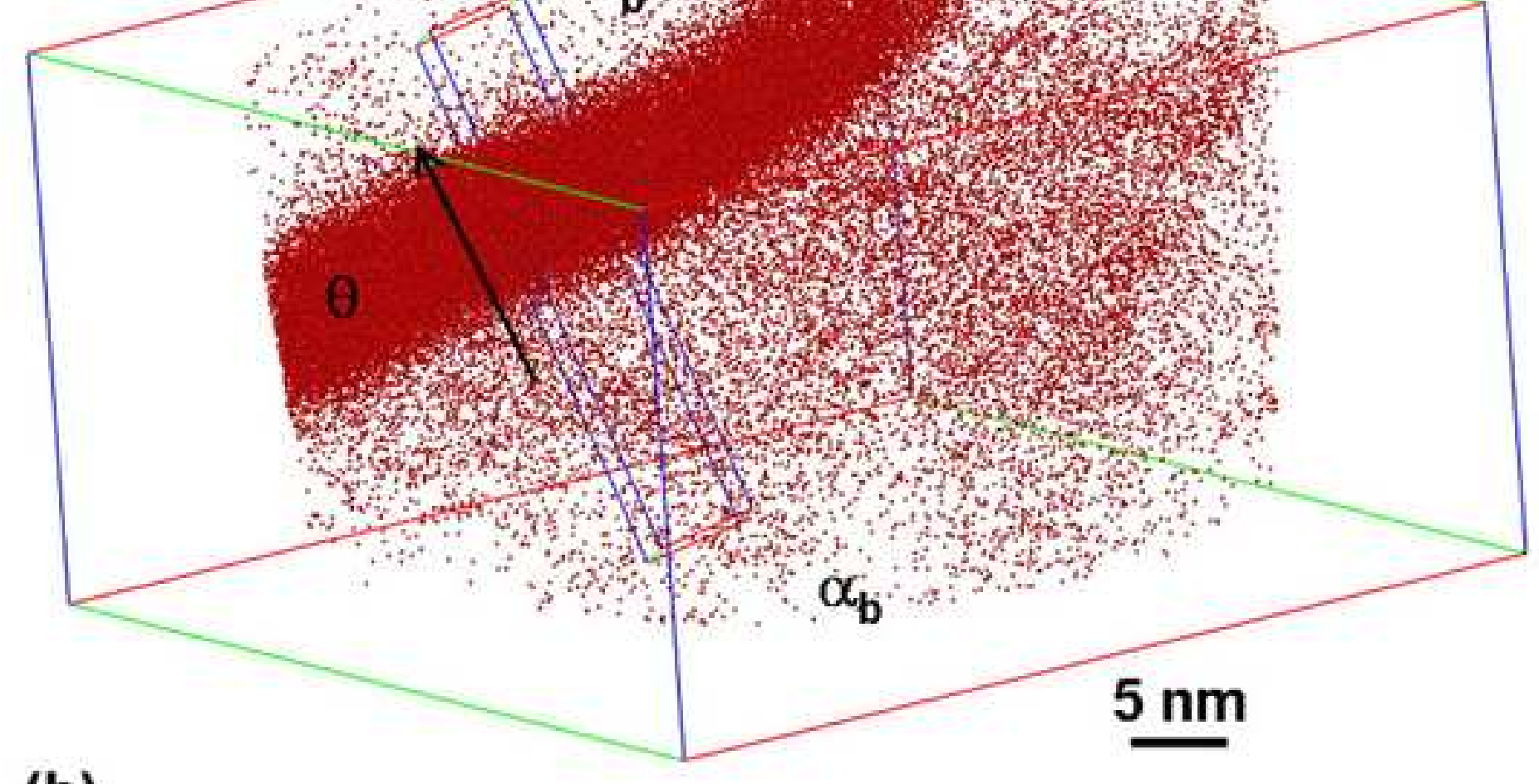

$\therefore \alpha_{b}$ 


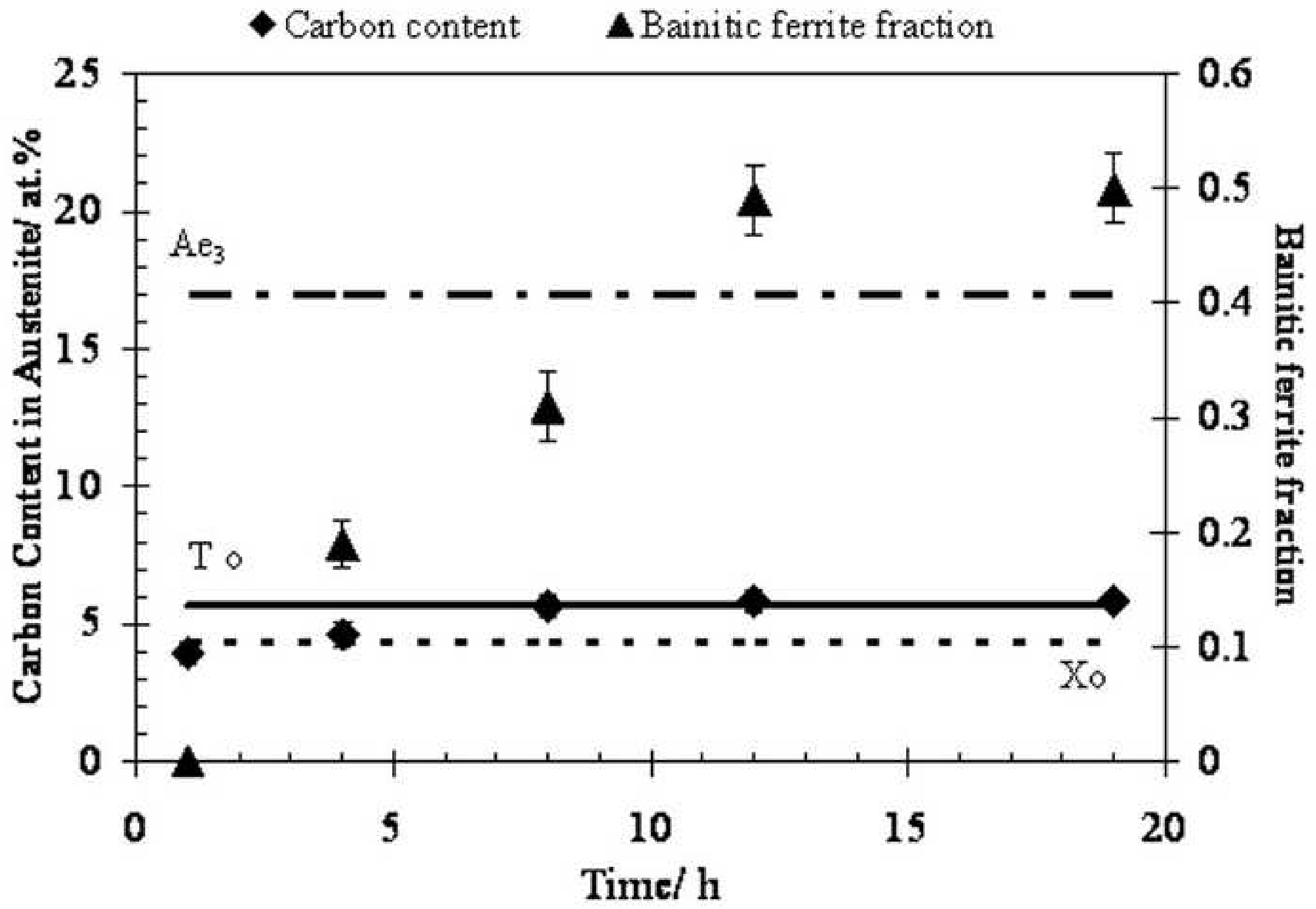



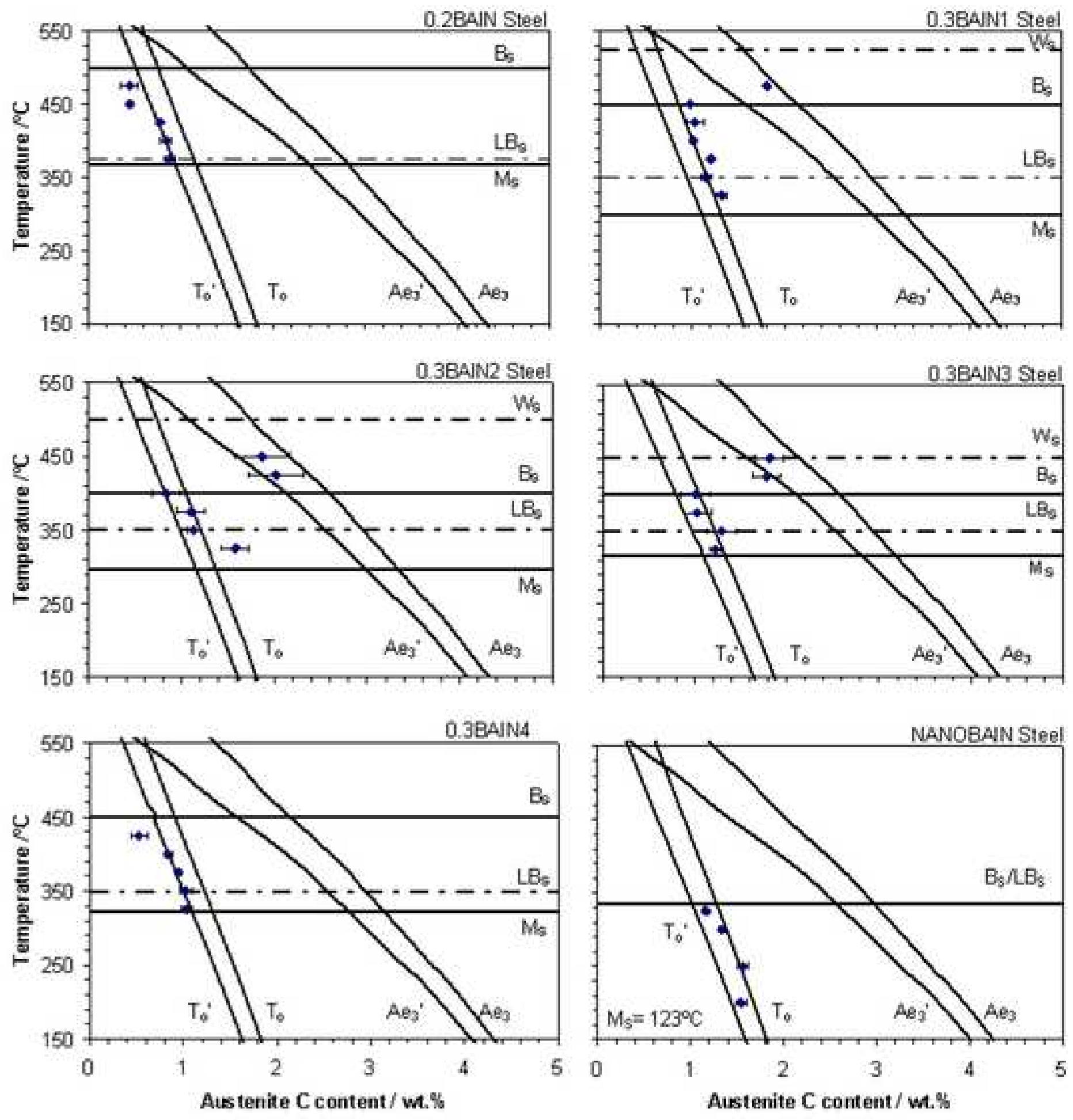


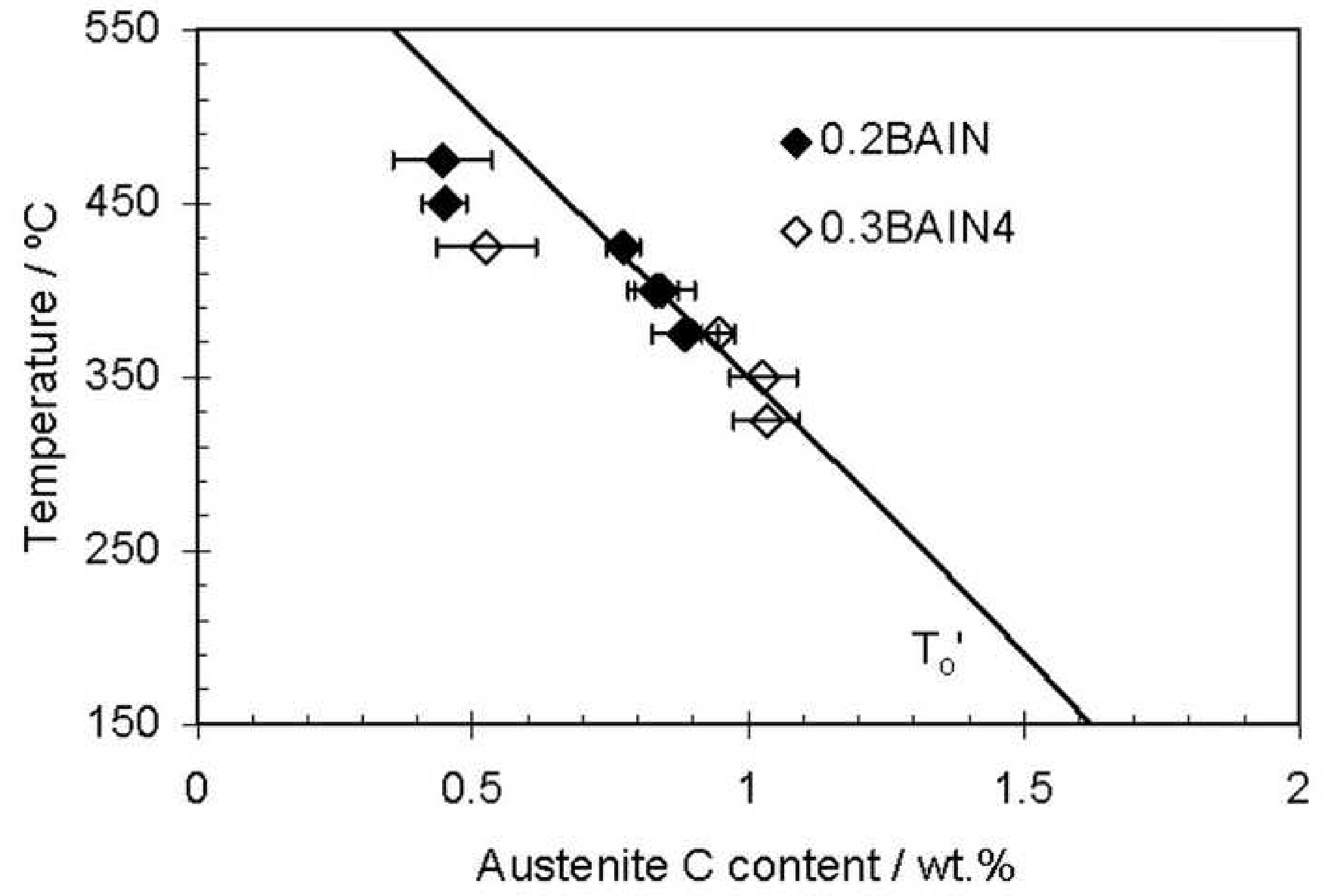


(a)

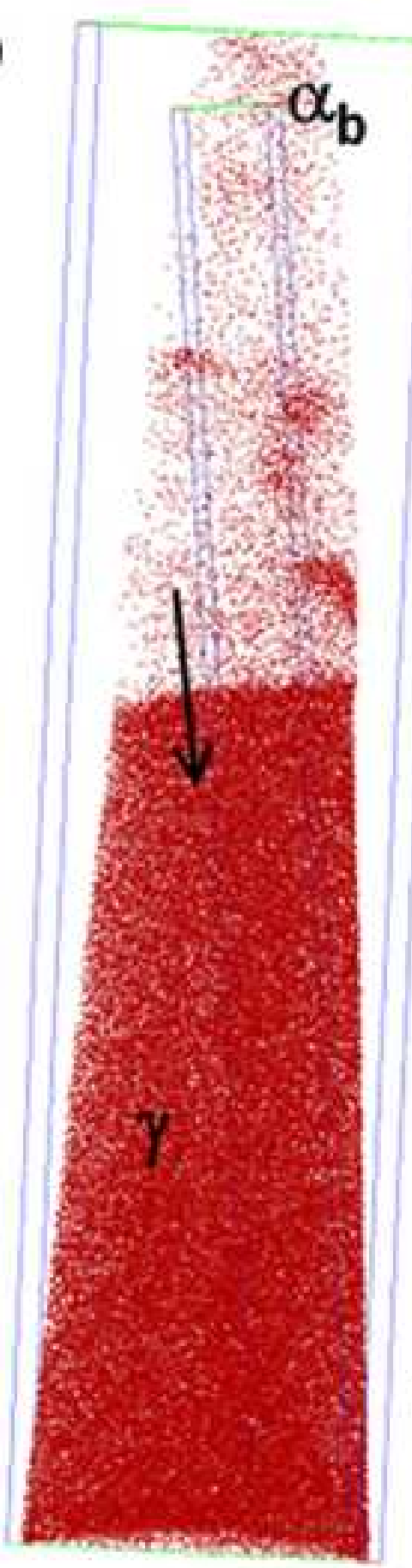

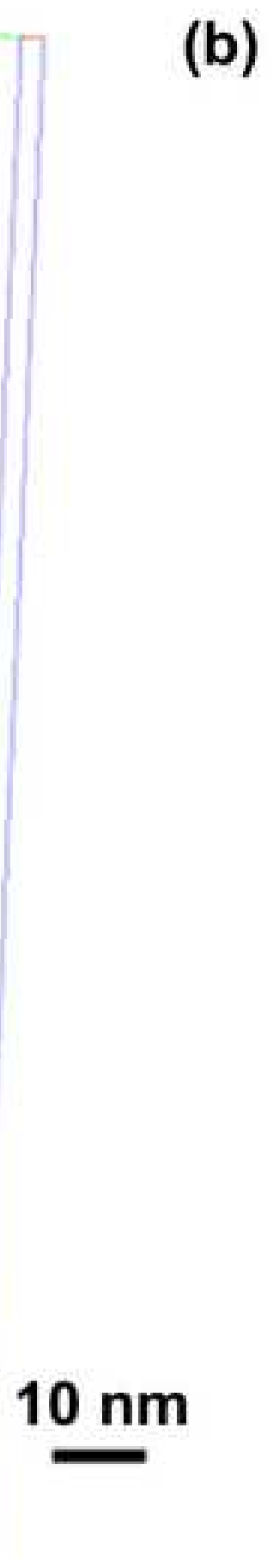

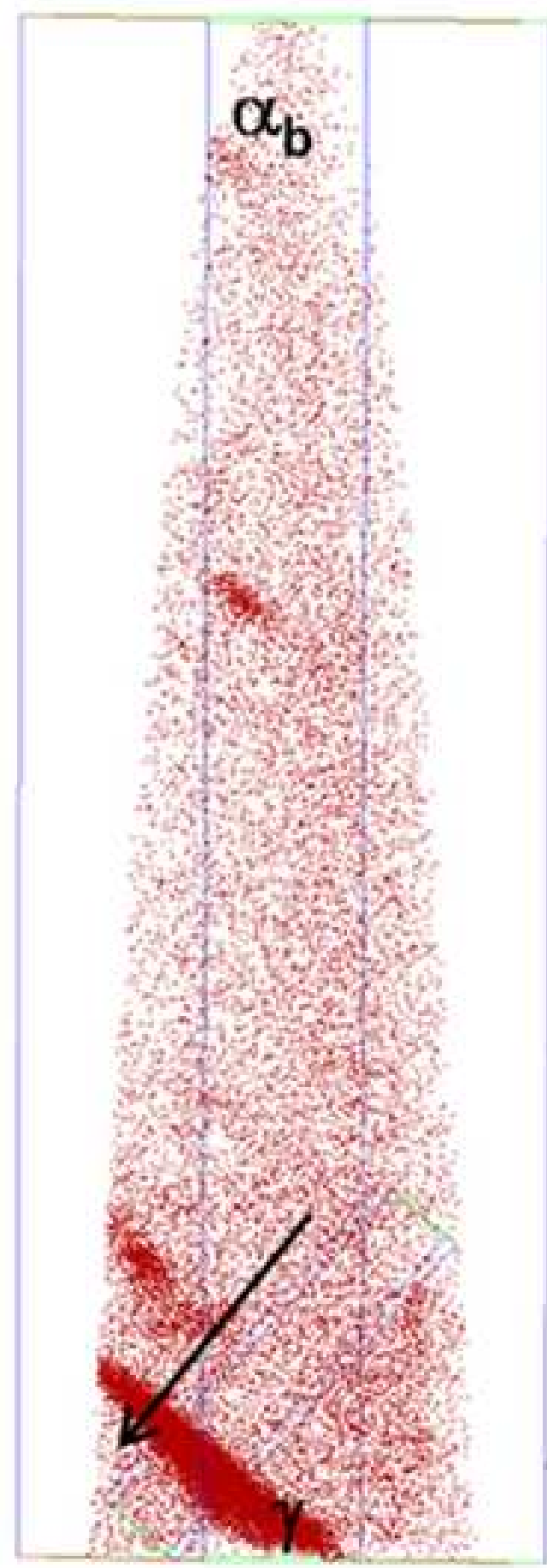

$10 \mathrm{~nm}$
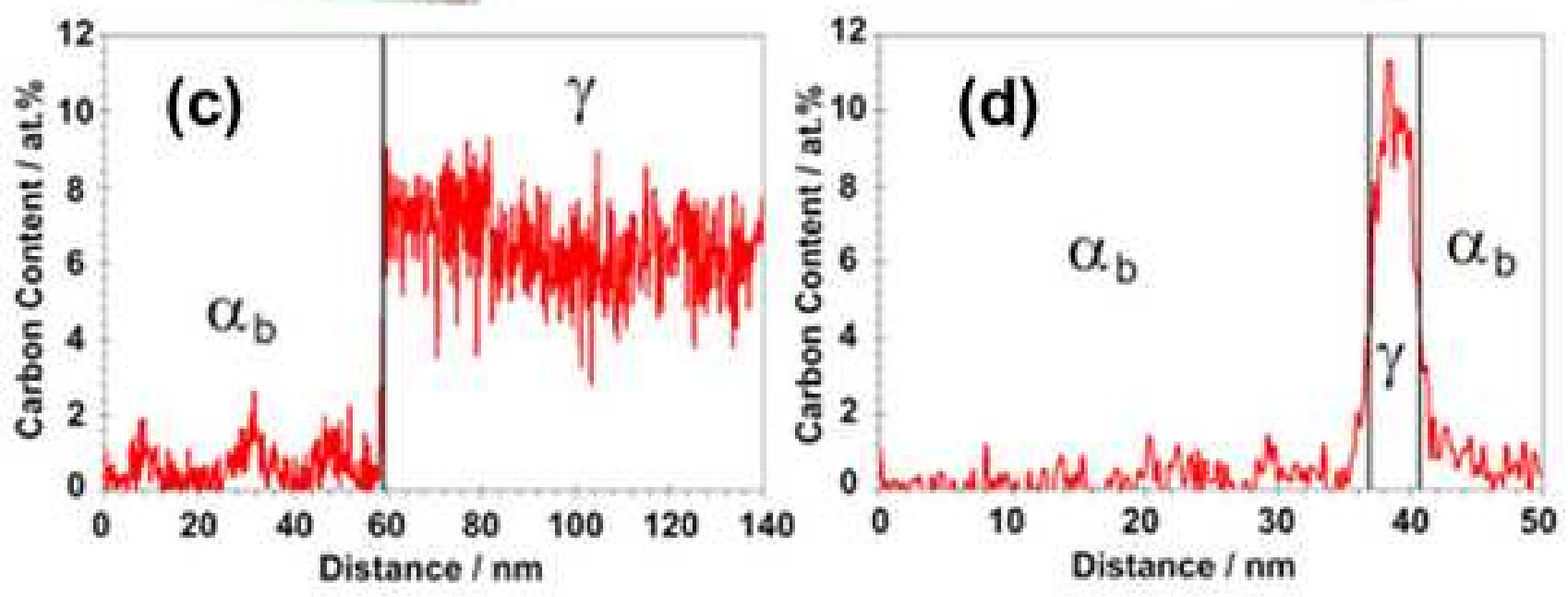